when plants are examined four to five weeks after having been transplanted into the contaminated soil, the presence of the largest root swellings is associated with the more favourable conditions for infection as indicated by the number of infected plants. During the progress of an experiment, the $p H$ value of soil which had been adjusted to 75 by the use of calcium hydroxide or calcium oxide usually fell to about $p H 7.0$; the $p H$ value of soil similarly adjusted by the use of calcium carbonate underwent less change.

In artificially contaminated soils treated with calcium hydroxide, infection was recorded in greenhouse experiments when the initial $p H$ value of the soil was 7.8 in a sandy loam or 7.9 in a clay soil, falling to $p \mathrm{H} 7.1$ and 7.2 respectively at the end of the experiment five weeks after transplanting the seedlings.

The results obtained in this investigation indicate that the efficacy of lime for controlling $P$. brassicae will be determined by the interaction of such soil factors as temperature, moisture and spore load.

[July 13.

${ }^{2}$ Monteith, J., J. Agric. Res., 23, 549 (1924).

2 Wellman, F. L., U.S. Dep. Agric. Tech. Bull., 181 (1930).

$\checkmark$ Naumova, N. A., Bull. Plant Protect., Ser. 2, Phytopath., Teningr. 3, 32 (1933). (Abstract in Rev. App. Mycol., 13, 141.)

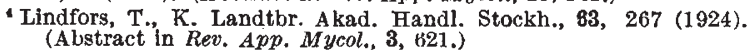

'Chupp, C., Phytopath., 18, 301 (1928).

- Potts, G., Trans. Brit. Mycol. Soc., 19, 114 (1935).

'Larsnn, R. H., and Walker, J. C., J. Agric. Res., 48, 749 (1934).

' Haenseler, C. M., Phytopath.. 27, 130 (1937).

- Muskett, A. E., Ann. Bot. (N.S.), 2, 699 (1938).

${ }^{10}$ Muskett, A. E., and Colhoun, J., Ann, Bot. (N.S.), 6, 219 (1942).

${ }^{11}$ Muskett, A. E., Ann. Bot. (N.S.), 1, 763 (1937).

\section{THEORY AND PRACTICE OF ION EXCHANGE}

$\triangle$ SYMPOSIUM on the "Theory and Practice of Ion A Exchange" was held at Buckland House, Buckland, Berks, during September 24-25. The meeting was arranged at the invitation of the Physical Chemistry Group of the Atomic Energy Research Establishment, Harwell, and was organized by Dr. E. Glueckauf (Harwell), who in his opening remarks pointed out that it was primarily designed to enable workers in this field to compare results and to discuss the implications of recent work.

The first paper, from Dr. B. A. J. Lister (Harwell), was entitled "Applications of Ion Exchange in the Inorganic Field". After reviewing the progress in recent years in the use of synthetic ion exchangers in separation processes, he discussed some of his recent investigations (with Miss L. A. MeDonald) by ion exchange methods into the solution chemistry of zirconium and hafnium. Dr. Lister described methods of determining the ionic charge and degree of the cation-anion complexing of the zirconium species in strong acid solutions. Diffusion measurements in resins of different cross-linkage were also used for assessing ionic diameters. In this way he was able to establish the presence of such species as $\left[\mathrm{Zr}(\mathrm{OH}) \mathrm{NO}_{3}\right]^{+}$ and $\left[\mathrm{Zr}\left(\mathrm{NO}_{3}\right)_{2}\right]^{2+}$. The type of species present depended markedly on the anion and on the acid concentration of the solution.

Dr. J. D. H. Strickland (Chemical Inspectorate, Woolwich) illustrated a novel use of an anion exchange resin to determine the ionic charge on trace amounts of an anionic complex of nickel in alkaline solution. By plotting the logarithm of a function of the amount absorbed against the concentration of hydroxyl ions in solution, a straight line of slope equal to the ionic charge is obtained, when the concentration of the complexed species in the exchanger and in solution is small by comparison with the concentration of alkali. He also outlined work in progress to find ion exchange constants and citrate complexing constants at various temperatures for individual rare-earth and other trivalent cations.

Dr. S. M. Partridge (Low Temperature Research Station, Cambridge) contributed a paper on "The Use of Ion Exchangers in Organic Chemistry", in which he described both the displacement and elution techniques as applied to amino-acids and proteins. After illustrating typical applications of these techniques for separating simple amino-acids, he went on to discuss how far it is possible to use the method for the separation of proteins. It is remarkable that, as Stein and Muore have shown, the rate of equilibration of protein with ion exchangers seems to be very little slower, if at all, than the rate for amino-acids, although only a fraction of the total capacity is utilized. Presumably this is because, unlike the free amino-acids, proteins do not travel far into the exchanger before they becorne bound to it.

In the discussion on the foregoing papers, Prof. C. W. Davies (University College of Wales, Aberystwyth) described the separation of organic acids from grass extract by anionic exchange. Dr. J. F. Duncan (Harwell) pointed out theoretical objections to the use of ion exchange for determining ionic activity coefficients in solutions and the limitations which might be expected in the method. Dr. G. Waind (Harwell) supported the argument by describing results obtained with trace amounts of cobalt nitrate when equilibrated with a lithium-saturated exchanger in the presence of different concentrations of lithium nitrate.

Next came two contributions from the Chemical Research Laboratory, Teddington. In the first paper D. K. Hale discussed the properties desirable in an exchanger and described how different types of exchangers may be prepared and characterized. Measurement of swelling of the co-polymer, for example, can be used as a measure of the degree of cross-linking, and simple relations were reported between the swelling of unsulphonated resins of different cross-linkage in toluene and the swelling in water after sulphonation. Although one can use such tests to establish that two exchangers possess similar overall 'porosities', there is no direct evidence about how the cross-linking agent (for example, divinyl benzene) distributes itself throughout the resin. The capacity of a simple sulphonated polystyrene appears to be limited to one $\mathrm{SO}_{3} \mathrm{H}$ group per benzene ring. The other paper, by $\mathrm{D}$. Reichenberg, described some careful experiments to determine the water and acid uptake of exchangers with a content of 2-25 per cent divinyl benzene when immersed in solutions of hydrochloric acid. His experiments have established beyond doubt that the water in the exchanger is, within experimental error, identical in density with what it would be outside the exchanger. He showed that there is a linear relation between the weight of water taken up and the volume of swollen exchanger in water over a wide range of cross-linking, extrapolating to a value slightly less than the specific volume of the dry resin. The significance of change in cross-linking on the distribution of ions in the potassium/hydrogen, sodium/hydrogen 
and sodium/potassium exchange systems was illus. trated, and some remarks were made on the observed slower exchange-rates of exchangers of higher crosslinking.

Prof. Davies spoke next on "Electrochemical Behaviour and Applications of Ion Exchangers" under three heads. First, he mentioned the potentiometric measurement of cation activities by concentration cells. Second, he reviewed the work of Heymann and O'Donnell as an example of how the conductivity of ion exchangers might be measured by an A.c. technique and pointed out the disadvantages of their technique. Some of the work in progress in Prof. Davies's laboratory at Aberystwyth on the determination of the conductivity of hydrogen- and potassium-saturated exchangers at concentrations up to $1 M$ which seem to show some anomalies was also mentioned. Lastly he discussed the possibilities of separating ions by ionophoresis and electrodialysis under the influence of direct current. In the discussion, contributions were made by Dr. G. C. Barker and H. Small on precision measurements of resin conductivities in progress at the Atomic Energy Research Establishment, Harwell, showing that, when a hydrogen resin is gradually changed to a sodium resin, the conductivity is not linear with change in composition. Dr. Barker also reported some frictional effects observed with exchangers saturated with different cations. Dr. T. R. E. Kressman (Permutit Co., I.td.) reported his observations in using membranes of a cation-exchange resin of the sulphonated phenol-formaldehyde type in concentration cells. He said that provided pure solutions were used and the concentrations lay between certain limits, the potentials obtained when the membrane separates two solutions of the same salt at different concentrations are reproducible and are those predicted by the Nernst equation, $E=\left(R^{\prime} I / F\right) \log a_{1} / a_{\mathbf{y}}$. The activity functions which give the best agreement with this equation were the mean activities of cation and anion and not the single ion activities. When mixtures of salts were used, the potentials were generally complex functions of the activities of the individual salts. When the membranes separated pure solutions of salts having a common cation and different anions, the potential was that predicted by the Nernst equation plus a constant determined by the nature of the anions. Results were given for salts having sodium, potassium, ammonium and hydrogen as the positive ion, and it was shown that the limits between which they fitted the Nernst equation were wider the higher the ratio of the mobilities of the cation and anion in the membrane. With potassium chloride the $p \mathrm{~K}$ limits were approximately 1 and 3 , while with sulphuric acid the $p \mathbf{H}$ limits were -0.2 and 4. Dr. Glueckauf pointed out that, while such measurements are very successful in the case of cations of high activity coefficients, they are bound to fail in the cases of potential measurements with 'resinates' of low activity coefficients. He produced data showing the extremely high nitrate uptake of silver 'resinates' which would adversely affect the transport number.

Dr. J. A. Kitchener (Imperial College of Science and Technology, London) completed the programme of the first day with a paper on "The Kinetics of Ion Exchange". In a general review, he discussed in particular the implications of the divergences which seem to be obtained near zero time when a film diffusion mechanism is fitted to the $\sqrt{ } t$ law, and pointed out that such divergences seem to be very frequently obtained. The desirability of further theoretical study was stressed in the general discussion which followed. Dr. R. F. Hudson (Queen Mary College, London) remarked on the difficulties of obtaining an adequate mathematical treatment for a mixed particle-film diffusion mechanism, and Dr. A. Wasserman (University College, London) mentioned several interesting aspects of the kinetics and equilibrium of ion exchange in alginates.

The following day was devoted almost entirely to theoretical aspects of ion exchange. The opening paper, by Dr. Duncan, surveyed the existing theories of ion exchange and related subjects. He first considered what experimental data are necessary for an adequate understanding of the theory. He pointed out that the effect of the anion on the separation factor of two cations, which has frequently been observed, can be explained by taking account of the activity coefficients of the electrolytes in the aqueous solutions. In the case of heterovalent exchange these cannot be neglected even in solutions as dilute as $0.02 \mathrm{M}$. He then emphasized the close similarity of behaviour during recent years using highly crosslinked synthetic exchangers with that obtained using clays, bentonites, and synthetic and natural zeolites during the period 1900-25. This merits a careful re-assessment of the results obtained by the earlier authors using naturally occurring exchangers. The second half of Dr. Duncan's paper dealt with the theories put forward to explain the observed variation in mass product plot. The empirical approaches of Rothmund and Kurnfeld, and also of Wiegner, have latterly been replaced by semi-empirical equations in which specific assumptions have been made for the activities of ions in the exchanger phase (for example, Vanselow, Boyd, Keilland, Gapon, Duncan and Lister). All these are limited to a greater or lesser extent in their range of applicability. The statistical approach of Overstreet was given special discussion, as was the treatment put forward by Gregor.

In the ensuing discussion, Dr. Kressman explained observations concerning the apparent non-equivalence of exchange when magnesium ions are used, which is due, he believed, to the formation of $\mathrm{MgOH}^{+}$ or $\mathrm{MgCl}^{+}$species; Dr. Wasserman discussed the method used by him for drying alginate fibres without removing absorbed water; Mr. Hale referred to his experiments with large organic ions in which the distribution constant varied by several powers of ten; and J. K. Perring (Harwell) discussed a possible improvement on the Overstreet equation.

In the final paper of the session Dr. Glueckauf reported on the latest developments in the theory of cation exchange. He said that only if an ion exchanger is regarded unreservedly as an aqueous electrolyte (for example, sodium 'resinate') dissolved in the swelling water which the exchanger absorbs can properties such as osmotic and activity coefficients be unambiguously determined. He showed that the water contents of resins at known water activities (determined isopiestically by G. P. Kitt (Harwell)) permit the calculation of the osmotic coefficients $\nu \varphi=\left(\ln a_{w}\right) / 0.018 \bar{m}_{t}$; and the trend of these curves indicates that $\nu$, the number of freely mobile ions, is unity, which means that the fixed anionic groups of the exchanger do not contribute to the ideal statis. tical entropy terms of the free energy. By comparing the water-vapour pressures ( $a_{w}$ and $\bar{a}_{w}$, respectively) of two exchangers at the same concentration (in moles) $1,000 \mathrm{gm}$. swelling water), one of high cross-linking and 
the other of effectively zero cross-linking, it is possible to calculate the swelling pressure $P$ of the highly crosslinked resins from the thermodynamically derived equation $\ln a_{w} / \bar{a}_{w}=0.018 \mathrm{P} / R T$. Within the experimental error, this pressure was found to be a linear function of the resin extension (Hooke's law). It was shown that one is justified in the case of the resinates of hydrogen, lithium, sodium and potassium (though not of silver) in using the Harned rules for activity coefficients of mixtures, and that the knowledge of $\nu \varphi$ for different resinates permits of a good estimate of the ratio of the activity coefficients of these resinates. This, and the knowledge of $P$, permits the prediction of separation factors under varying conditions of the external solution and of the internal resin structure as modified by differences of crosslinking. These predictions have largely been con. firmed by experiment. Dr. Glueckauf also showed that the amount of electrolyte taken up and the water lost by a cation exchange resin when in contact with a solution containing the same cation can serve to determine the absolute value of the thermodynamic activity of the resinate. He demonstrated from experimental data of Pepper and Reichenberg, and of Prof. Davies, that for hydrochloric acid which is in contact with sulphonated polystyrenes of different cross-linking there is a surprisingly high dissociation of the hydrogen resinate at $20 M$ concentrations, comparable with that of perchloric acid.

Replying to Dr. Wasserman, Dr. Glueckauf said that the implications are that the cations in the wet exchanger are in a state of mobility somewhere between that of nitrates and chlorides of similar ionic strength. He also pointed out that an increase in experimental accuracy would be required to draw further theoretical conclusions concerning the interaction of ions in the resin phase. In the discussion, Dr. Duncan quoted similarly calculated values for 'Dowex-50' in the presence of sodium iodide, sodium bromide and silver nitrate, which, within the limits of error, confirm the conclusions derived from the more sensitive data at lower cross-linking.

The final session was entirely a discussion period. Dr. Hudson gave an interesting account of the significance of ion exchange phenomena in the behaviour of wool, one of the most ancient ion exchangers. He showed that, in some cases, acid absorption by wool does not follow that to be expected on a simple particle-diffusion mechanism, although assuming a linear adsorption isotherm for the unadsorbed acid in the wool, the concentration of which is calculated by the Donnan membrane concept, theory and experiment can be brought into line.

Dr. K. W. Pepper (Chemical Research Laboratory, Teddington) described recent applications of ion techniques in the United States, including the separation of sugars on strongly basic resins using sugarborate anionic complexes, the separation of nucleic acid degradation products, and the absorption of complex metallic anions from concentrated hydrochloric acid solutions on strongly basic resins.

Prof. Davies summed up the results of the conference, which, he said, greatly stimulated further research activities not only on account of the mass of new experimental facts but also by the new interpretation, which though not explaining every detail unified a large number of data on the behaviour of ion exchangers. He also reminded the conference of the confusion arising from individual symbolism, and said that the scientific societies of Great Britain have agreed to use square brackets [] for concentration units, \{\} for activities, $\gamma$ for stochiometric activity coefficients, and $f$ for activity coefficients on a molar concentration scale; he supported the use of 'bars' for properties connected with the resin phase, as opposed to the external aqueous phase.

\section{J. F. DUNCAN}

\section{BRITISH GELATINE AND GLUE RESEARCH ASSOCIATION}

\section{OPENING OF THE LABORATORIES}

$\mathrm{O}^{\mathrm{N}}$ November 29, 1951, the laboratories of the British Gelatine and Glue Research Association, at $2 a$ Dalmeny Avenue, Holloway, London, N.7, were opened by Sir Roger Duncalfe, chairman of British Glues and Chemicals, Ltd. The opening ceremony was preceded by a reception and luncheon at Beales Restaurant, Holloway. In proposing the toast of the Association, Sir Roger referred to the state of the industry in the early days of the century, when he had just joined a glue works and was studying in his spare time with Prof. Kipping and his colleagues Drs. Sudborough, Lander, Caven and Sand. Scientific control was almost unknown, and the industry was faced with heavy competition. Before the First World War the first steps towards the use of science, towards greater technical efficiency and towards co-operation in the industry had been taken, so that the War found the industry prepared to meet the heavier burden imposed on it. The extension and strengthening of the manufacturers' federations, the introduction of standard methods of test, and the expansion of production resulting from technical progress in the period 1919-39, enabled the whole of the requirements of the industries to be met during the Second World War. In the post-war years the aim of the industry has been to achieve a credit balance of trade, thereby reversing the pre-1939 position. This has in large measure been done.

Sir Roger then referred to the decision to concentrate the main effort of the Association in its early years on fundamental research, to prepare the industry scientifically for difficulties which may come, and to maintain the rate of progress. He emphasized the importance of wide contacts in order to make use of work in other laboratories. In conclusion, he showed the connexion of the work of the Association to the study of living matter.

Sir Ben Lockspeiser, secretary of the Department of Scientific and Industrial Research, supported Sir Roger's remarks. In his speech he directed attention to the very great gap which exists between carrying out scientific research and the exploitation of that research by industry. The application of research to industry does not occur automatically, but requires most careful consideration from both the scientific and the economic angles. While intelligible writing of reports assists in securing appreciation of the value of work in the industry, there must be sufficient scientific staff actually employed by firms to take full advantage of the research. The problem of developing the results of research beyond the laboratory stage is also one of very great importance.

Prof. F. J. W. Roughton, professor of colloid science in the University of Cambridge, also spoke in support of Sir Roger Duncalfe. He underlined the very 